\title{
Drugged driving: Canada's laws lag behind
}

\section{Part III: Other countries enforce limits}

I $\mathrm{n}$ addition to setting a legal limit for cannabis, experts say that random roadside testing is the best deterrent for drug-impaired driving. Canada has neither. Meanwhile, seven US states, Australia and 16 European countries have set legal limits. And nine of the European nations plus Australia allow random roadside saliva tests.

Canadian law enforcers are waiting for an accurate roadside test to measure levels of cannabis use (CMAJ Mar. 16, 2015), but they may have a long wait because detecting impairment from cannabis is not as straightforward as detecting alcohol because of the complex nature of the drug and lack of conclusive research about the dose-effect of cannabis.

Other nations have gone ahead and implemented laws, says the President of the European Commission's Working Group on Alcohol, Drugs, Medicines and Driving Laws. Dr. Alain Verstraete stated in an email that, "The idea is the same as for alcohol, a legal limit is set. Not all people will be impaired with a [blood alcohol count] of 0.05 or 0.08 , but they will be sanctioned."

Once Canada establishes a limit, the next roadblock is testing. Random roadside testing is allowed in at least 10 countries. This is justified on the basis of its proven efficacy in reducing alcohol-impaired driving (WHO report Drinking \& Driving). There is also some evidence that people who are drug-impaired are less likely to drive when the perceived risk of apprehension is increased (Accident Analysis \& Prevention 2006;38:854-61).

But unlike some jurisdictions, Canadian police do not have the authority to demand screening tests without reasonable grounds for suspicion, such as erratic driving or the smell of marijuana. The requirement for reasonable grounds, means our laws are lagging behind other countries such as Australia, says Robert

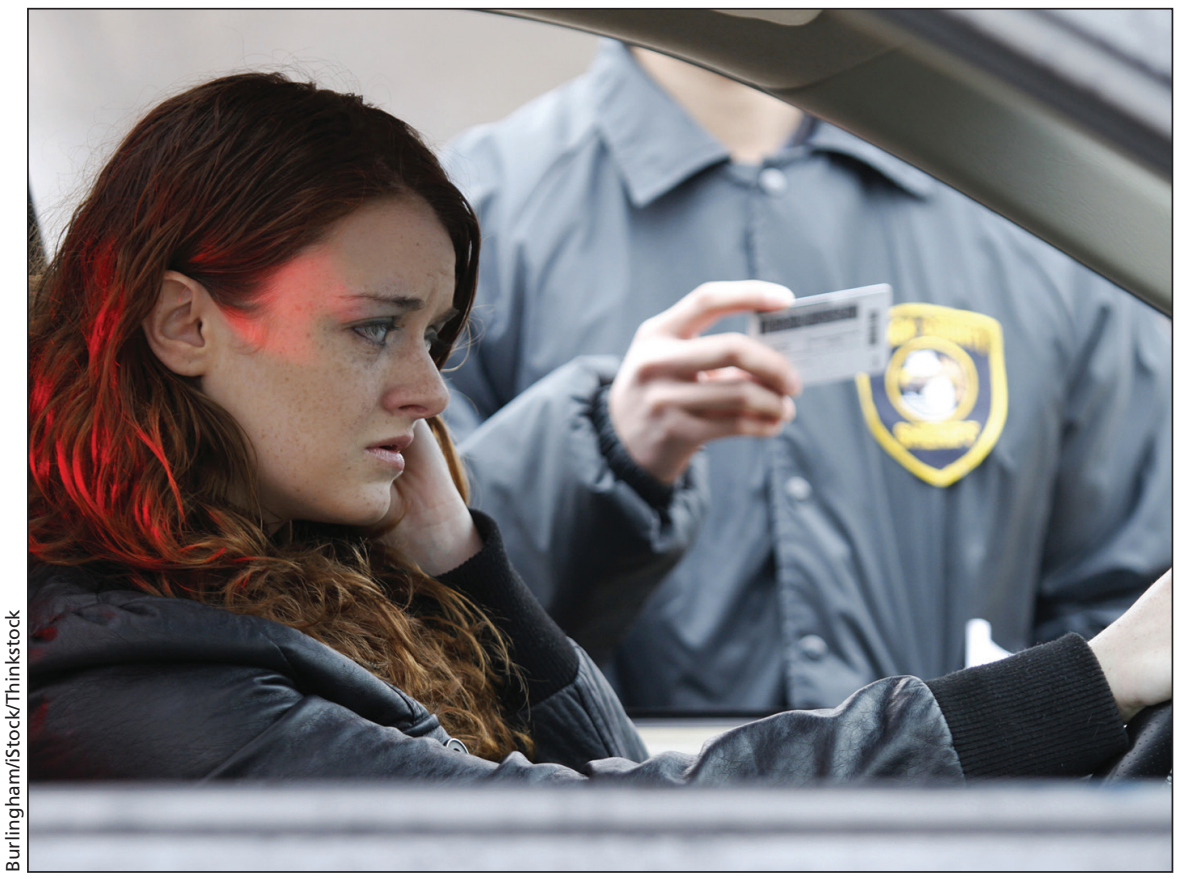

Random roadside testing for marijuana use deters drug-impaired driving.

Solomon, national director of Legal Policy for Mothers Against Drunk Driving (MADD) Canada.

And that delay may be coming with a high price. A study by the Victoria Institute of Forensic Medicine in Australia found that a person who had used cannabis was 2.7 times more likely than a drug-free driver to be involved in a fatal collision. In the state of Victoria, which implemented random screening in 2004, the percentage of drivers killed in motor-vehicle crashes with tetrahydrocannabinol (the active ingredient in cannabis) present in their body decreased from $19 \%$ in 2005 to $17 \%$ in 2013. All eight Australian states now have random screening. In other words, police don't require "reasonable grounds."

"What you want to do is screen millions of drivers," says Solomon. "That's what's reduced impaired driving in the rest of the world. Canada has a terrible record in terms of impaired driving [for alcohol] relative to comparable Organisation for Economic Cooperation and Development nations.
And the reason for that is that they have smarter laws."

The 2010 report Drugs and Driving by the Joint Transport Research Centre found that although Canada has one of the lowest rates of alcohol consumption, it has one of the highest rates of alcohol-related deaths. "We're making the same mistakes that we've made with alcohol, with cannabis," says Solomon

Under Canada's laws, if police have reasonable grounds to suspect alcohol or drugs, then they can demand a standardized field sobriety test, which includes a walk and turn, eye exam and standing on one leg. If the person fails, and then blows zero on a breathalyzer, the officer can demand a drug recognition evaluation (DRE). This involves 12 physical and coordination tests and an analysis of saliva, blood or urine conducted at the police station.

Michael Gendron, communications and government relations officer at the Canadian Police Association, agrees that relying on an officer's perception of impairment is the biggest challenge; “...it's not like a breathalyzer where 
it's cut and dried, you are impaired or not impaired."

Solomon says that Canada's approach is expensive and inefficient. Training one DRE officer costs \$17000. Canada has trained 800 officers, but because of transfers and retirements, only 491 were available to conduct DREs in 2012.

Although the standardized field sobriety test and DRE, which were implemented in 2008, are steps in the right direction and better than nothing, Solomon says the current system doesn't have a "sufficient deterrent impact because it will not increase the perceived risk of apprehension." It is also grossly underenforced.

The Canadian Centre on Substance Abuse estimates 15.6 million trips were made by people after smoking cannabis in 2012, but only 1126 drug-impaired driving charges were laid. "If you work that out, you have to smoke a joint and drive 16000 times before you are charged once," says Solomon.

Conviction data for drug-impaired offences are not available, because the courts do not distinguish between alcohol- and drug-impaired offences. But Solomon says a substantial number of drug-related cases are thrown out, because DRE tests cannot prove beyond a reasonable doubt that the driver was impaired at the time.

"Our current laws don't work," says Solomon. "While we do need more research, we know enough to be doing a better job." - Dane Wanniarachige, London, Ont.

CMAJ 2015. DOI:10.1503/cmaj.109-5036 